\title{
Tessituras da memória: leituras literárias e o ser negro pelo olhar de professores de uma escola de ensino médio no Cariri cearense
}

\author{
Thessituras of memory: literary readings and the black being by the gaze of teachers of a high \\ school in the region of Cariri-Ceará \\ Tesituras de la memoria: lecturas literarias y el ser negro por la mirada de profesores de una \\ escuela secundaria de la región Cariri de Ceará
}

Recebido: 08/12/2021 | Revisado: 13/12/2021 | Aceito: 21/12/2021 | Publicado: 03/01/2022

\author{
Bruna Ataíde de Lima Lopes \\ ORCID: https://orcid.org/0000-0003-4236-1472 \\ Universidade da Integração Internacional da Lusofonia Afro-Brasileira, Brasil \\ E-mail: brunataide@aluno.unilab.edu.br \\ Eliza Távora de Albuquerque \\ ORCID: https://orcid.org/0000-0003-1740-4805 \\ Universidade da Integração Internacional da Lusofonia Afro-Brasileira, Brasil \\ E-mail: eta@aluno.unilab.edu.br \\ Andréa Moura da Costa Souza \\ ORCID: https://orcid.org/0000-0003-1059-0756 \\ Instituto Federal de Educação, Ciência e Tecnologia do Ceará, Brasil \\ E-mail: andrea.souza@ifce.edu.br \\ Anna Érika Ferreira Lima \\ ORCID: https://orcid.org/0000-0002-8290-9802 \\ Instituto Federal de Educação, Ciência e Tecnologia do Ceará, Brasil \\ E-mail: annaerika@ifce.edu.br
}

\begin{abstract}
Resumo
O presente trabalho tem como objetivo identificar memórias sobre a presença e caracterização de personagens negros/as na trajetória de leitura literária de professores de Ensino Médio de uma escola da região do Cariri cearense. Para tanto, utilizou-se o formato de pesquisa de abordagem exploratória, quali-quantitativa, realizando estudos bibliográficos em livros, artigos científicos e dissertações, além da aplicação de um questionário de coleta de dados para educadores da já referida instituição de ensino. Assim, a análise das informações coletadas foi feita com base nas leituras realizadas durante o estudo bibliográfico sobre a temática e considerando o ser humano como sujeito que se constrói a partir das relações histórico-sociais. Como resultados, obteve-se elementos que indicam o apagamento do personagem negro/a da memória, a ratificação do mito da democracia racial e do embranquecimento da população brasileira, a identificação do negro/a com a marginalização, miséria, submissão; mas também foram obtidos componentes que indicam uma (re)leitura da história e apontam para o processo de luta contra o racismo e para a afirmativa da cultura e identidade negra. Dessa forma, a literatura mostra-se como potente instrumento interventivo para construção de novos conhecimentos e vivências.
\end{abstract}

Palavras-chave: Literatura; Memória; Ser negro.

\begin{abstract}
The present work aims to identify memories about the presence and characterization of black characters in the trajectory of literary reading of high school teachers of a school in the region of Cariri-Ceará. For this purpose, we used the research format of exploratory, quali-quantitative approach, performing bibliographic studies in books, scientific articles and dissertations, in addition to the application of a data collection questionnaire for educators of the aforementioned educational institution. Thus, the analysis of the collected information was based on the readings made during the bibliographic study on the theme and considering the human being as a subject that is constructed from the historical-social relations. As results, we obtained elements that indicate the black character's payment of memory, the ratification of the myth of racial democracy and the whitening of the Brazilian population, the identification of the black with the marginalization, misery, submission; but components were also obtained that indicate a (re)reading of history and point to the process of combating racism and to the affirmative of black culture and identity.components were also obtained that indicate a (re)reading of history and point to the process of combating racism and to the affirmative of black culture and identity. Thus, the literature is shown as a powerful interventional instrument for the construction of new knowledge and experiences.
\end{abstract}

Keywords: Literature; Memory; Be black. 


\begin{abstract}
Resumen
El presente trabajo tiene como objetivo identificar la presencia y caracterización de personajes negros en la trayectoria lectora literaria de profesores de una escuela secundaria de la región Cariri de Ceará. Para eso, se utilizó el formato de investigación exploratoria, cuali-cuantitativa, realizando estudios bibliográficos en libros, artículos científicos y disertaciones, además de la aplicación de un cuestionario de recogido de datos para educadores de la mencionada institución educativa. Así, el análisis de la información recopilada se basó en las lecturas realizadas durante el estudio bibliográfico sobre el tema y considerando al ser humano como un sujeto que se construye a partir de relaciones histórico-sociales. Como resultado, obtuvimos elementos que indican el borrado del carácter negro de la memoria, la ratificación del mito de la democracia racial y el blanqueamiento de la población brasileña, la identificación de los negros con la marginación, la miseria, la sumisión; pero también se obtuvieron componentes que indican una (re) lectura de la historia y apuntan al proceso de lucha contra el racismo y la afirmación de la cultura e identidad negras. Así, la literatura se muestra como un poderoso instrumento intervencionista para la construcción de nuevos conocimientos y experiencias.
\end{abstract}

Palabras clave: Literatura; Memoria; Ser negro.

\title{
1. Introdução
}

O modo como os personagens negros/as foram representados/as ao longo da história contribui, de forma decisiva, para a atualização e manutenção do racismo no Brasil. Isso porque, segundo um levantamento histórico feito por Silva (2009), observa-se que a representação do/a negro/a na literatura remete ao passado escravocrata, revela uma relação de servidão frente aos brancos e, mesmo quando se deu início a um processo de denúncia do racismo por meio dos textos literários, ainda há marcas de sulbaternização e/ou de abordagem do personagem negro/a pelo viés da comiseração.

Em consonância com esse contexto, Adichie (2019, p.23) assevera que "assim como o mundo econômico e político, as histórias também são definidas pelo princípio de $n k a l i{ }^{l}$ : como elas são contadas, quem as conta, quando são contadas e quantas vezes são contadas depende muito do poder (influência) de quem conta a história. O poder é a habilidade não apenas de contar a história de outra pessoa, mas de fazer que ela seja sua história definitiva”. De tal maneira, percebemos o quanto a literatura canônica eurocentrada contribuiu para estigmatização do negro.

Partindo da indagação: Como está presente, na trajetória de leitura literária, de professores/as de Ensino Médio a imagem do "ser negro" ? objetiva-se trazer à tona elementos necessários para discussão sobre a imagem dos personagens negros/as nos textos literários lidos por professores de ensino médio, discorrendo sobre como isso pode reforçar as estruturas para constante atualização do racismo.

Reconhecendo que nosso imaginário mobiliza posicionamentos externos (atitudes, palavras, comportamentos), assim como internos (valores, crenças, emoções), trataremos a memória como um elemento constituinte do sentimento de identidade e que interfere fortemente na maneira de perceber o mundo e de tomar decisões (Sousa, 2005). Assim, decidimos investigar o que revela o percurso de leituras literárias feitas por professores/as de uma escola de ensino médio a respeito do seu olhar sobre o ser negro.

Além disso, parte-se da afirmativa de que a escola é um dos espaços mais importantes para formação da identidade do indivíduo e que os/as professores/as são importantes agentes nesse processo, como destacam Silva e Boakari (2021, p. 05) ao afirmarem que

Um dos lugares mais marcantes da vida de uma pessoa é o espaço escolar. É nele que o contato com o outro se intensifica, e assim começa-se muito cedo a entender quem se é. Este processo se dá através da consciência de si, a partir de uma produção da autoimagem e, consequentemente da autoestima, a partir das relações que construímos com o outro, sejam alunos, professores, vigia, merendeira, secretária ou a escola em si. (Silva \& Boakari, 2021, p. 05)

\footnotetext{
${ }^{1}$ Palavra de etnia lgbo que, em tradução livre, quer dizer "ser maior do que o outro".

${ }^{2}$ Termo oriundo do trabalho de Silva (2009). Neste trabalho, foi tomado para significar a condição daquele/a que é negro/a na sociedade brasileira.
} 
De tal maneira, a importância deste estudo encontra-se, em primeiro momento, na possibilidade de revelar, a partir do relato de memórias e pelo viés das leituras literárias, a criação e manutenção de estereótipos sobre o "ser negro" no Brasil. Destacando-se, ainda, que a discussão dessa temática é relevante para sociedade pelo fato de o racismo estar presente em suas estruturas, então estas investigações possibilitam conhecê-lo e auxiliam no processo de busca por intervenções de combate à discriminação e ao preconceito racial, problemas sociais estruturais enfrentados em todos os âmbitos do país, inclusive nas escolas por meio dos livros e das atividades escolares .

Dados da PNAD ${ }^{3}$ Covid-19 mostram que, durante a pandemia, a taxa de desocupação, de trabalho informal e de insegurança alimentar cresceu para todos os grupos de raça ou cor, porém quando se compara esses números entre brancos e negros, percebe-se que para a população negra esses fatores foram mais intensos e ainda maiores quando se referem a mulheres negras. Isso ratifica a desigualdade determinada pela raça e sugere a emergência de práticas que visem intervir nessa realidade (IBGE, 2020).

Dessa forma, pensando a educação como dimensão social marcada pelas sequelas dessa conjuntura, mas ao mesmo tempo, como nos ensina Paulo Freire (1996), uma forma de intervenção no mundo, é que se justifica a relevância do presente estudo. O fazer docente comprometido com a discussão, reflexão e transformação dessa estrutura, exige, como dito nas palavras de Freire (1996, pp. 17-18), disponibilidade ao risco, aceitação do novo, rejeição a qualquer forma de discriminação, exige reflexão crítica sobre sua prática. Ademais, as Orientações Curriculares Nacionais para o Ensino Médio - OCNEM (2006) afirmam que "o estatuto do leitor e da leitura, no âmbito dos estudos literários, leva-nos a dimensionar o papel do professor não só como leitor, mas como mediador, no contexto das práticas escolares de leitura literária”.

Logo, o trabalho ora apresentado tem como objetivo geral identificar como os textos literários lidos por professores/as de Ensino Médio representam o "ser negro"; e objetivos específicos: identificar, no perfil da literatura presente na trajetória de educadores(as), a existência ou ausência de personagens negros(as) e como esses são retratados por professores de Ensino Médio.

\section{Metodologia}

Este artigo apresenta reflexões sobre a relação entre a leitura literária, praticada ao longo da vida, por educadores de uma escola de ensino médio, situada na região do Cariri cearense, e a formação do conceito do "ser negro" a partir dessas leituras.

Para tanto, realizou-se um estudo de campo, de caráter exploratório, que segundo Gonsalves (2007) é aquele que tem por objetivo fornecer informações para que estudos mais aprofundados sobre o tema sejam desenvolvidos. Quanto à natureza dos dados, utilizou-se a abordagem quali-quantitativa, verificando-se além dos dados estatísticos, a interpretação do fenômeno.

Para investigação, também foi realizada pesquisa bibliográfica, por meio de consultas em livros, artigos e dissertações presentes em bases de dados e bibliotecas virtuais, utilizando como descritores: literatura, leitura, racismo, memória, professor e suas combinações. Nesse percurso, buscou-se amparo nos estudos de Gouvêa (2005), Silva (2009), Cuti (2010), Oliveira (2017), Xavier, Fialho e Vasconcelos (2018) e Adichie (2019) e outros.

Além disso, foram utilizadas respostas de um questionário, parte integrante da pesquisa "Literatura negro-brasileira e relações étnico-raciais: possibilidades em 'Olhos d'água', de Conceição Evaristo.”, que vem sendo desenvolvida no percurso do Mestrado em Ensino e Formação Docente UNILAB/IFCE. Tal instrumento foi elaborado por meio da plataforma Google Forms, aplicado no mês de novembro de 2021, por intermédio do envio de link, via Whatsapp, para professores/as.

Esse instrumento de coleta de dados apresentou-se como viável, pelos cuidados em relação à prevenção da COVID-

\footnotetext{
${ }^{3}$ Pesquisa Nacional por Amostra de Domicílios.
} 
19, como também pelo processo exaustivo a que está submetida a maior parte dos/as educadores/as devido ao ensino remoto ou híbrido. No entanto, a utilização do questionário em plataforma virtual também carrega algumas limitações, como afirmativas genéricas ou evasivas por parte dos/as participantes e a impossibilidade de haver uma troca dialógica entre pesquisadores/as e interlocutores/as para aprofundamento de tais respostas, o que não nos propiciou trabalhar com informações mais detalhadas.

Decidimos que abordaríamos professores/as das quatro áreas do conhecimento: Linguagens, Matemática, Ciências Humanas e Ciências da Natureza, pois compreendemos que todos/as construíram, ao longo de suas trajetórias pessoal e profissional, um histórico de leituras, apesar de que alguns o fazem em maior grau e outros em menor. Além disso, levamos em

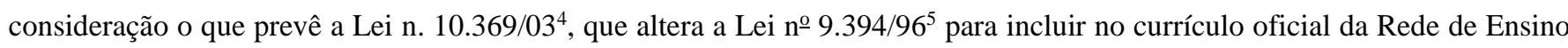
a obrigatoriedade da temática "História e Cultura Afro-Brasileira", já que esse dispositivo legal assegura que "os conteúdos referentes à História e Cultura Afro-Brasileira serão ministrados no âmbito de todo o currículo escolar, em especial nas áreas de Educação Artística e de Literatura e História Brasileiras".

Dos cinquenta e seis professores/as que receberam o questionário, trinta e seis responderam ao formulário que se apresenta como mostram as Figuras 1 e 2:

Figura 1. Parte 1: caracterização dos/as participantes.

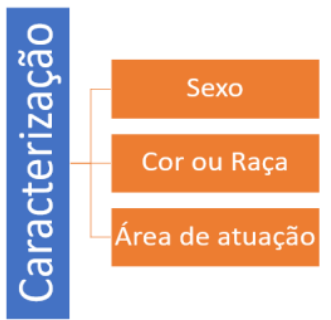

Fonte: Da pesquisa (2021).

Figura 2. Parte 2: questões sobre leitura literária, memória e a imagem do "ser negro".

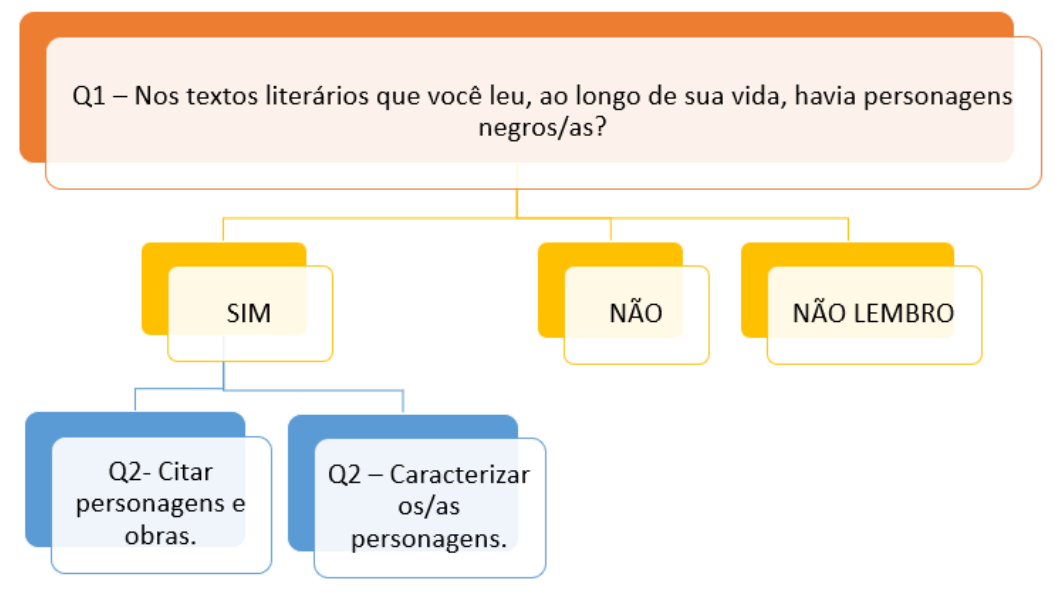

Fonte: Da pesquisa (2021).

\footnotetext{
${ }^{4}$ Em 10/03/2008, a Lei n. 10.639/03 foi substituída pela Lei n. 11.645/08, que inclui a cultura indígena. Decidimos citar, neste trabalho, a primeira ao invés da segunda, por considerá-la o principal marco em relação à inserção da cultura e história Africana e Afro-brasileira no currículo da Educação Básica. ${ }^{5}$ Lei de Diretrizes e Bases da Educação Nacional.
} 
Neste texto, utilizaremos o termo "questão 1" para tratarmos da Q1, e o termo "questão 2" para tratarmos do que se refere às informações contidas em Q2. Nas respostas dadas à questão 2, cada respondente está identificado pela letra "E" (educador/a), seguida do número que corresponde à ordem de interação com o instrumento de coleta de dados.

A partir das respostas coletadas e à luz das informações do acervo bibliográfico selecionado, analisamos em que medida esses personagens negros/as estiveram e/ou estão presentes na literatura lida pelos educadores/as, qual a percepção desses/as personagens e que memória foi construída pelos/as professores/as a partir deles.

\section{Resultados e Discussão}

Conforme Cuti (2010, p. 15), "no Brasil, durante os quatro primeiros séculos, escritores ficaram à mercê das letras lusas. O domínio político e econômico também se refletia no domínio cultural, incluindo a literatura". Fato este, que contribui de forma determinante para a elaboração de memórias individuais e coletivas sobre o que é ser negro no Brasil, como também causa impacto na formação da identidade negra e ainda resulta na constante atualização das categorias de supremacia branca, preconceito, discriminação e racismo.

Dessa maneira, muito do que reproduzimos hoje em discursos, comportamentos e práticas são fruto das memórias construídas ao longo da vida. Então considerando o que preceituam Xavier, Fialho e Vasconcelos (2018, p. 89) quando afirmam que “ $[\ldots]$ as Memórias, quando evocadas, podem reluzir e traduzir uma imensidão de rastros, marcas e pontos que a escrita ofuscou e não se preocupou em registrá-los, ou por menosprezo preconceituoso da História oficial, ou por desconhecimento/ irreconhecimento", propusemos essa investigação acerca das memórias sobre o "ser negro", construídas por professores de Ensino Médio, de uma escola na região do Cariri cearense.

O envio do questionário a todos os professores da escola partiu do pressuposto de que esse trabalho deve atravessar o currículo em todas as disciplinas e que a memória sobre o "ser negro" implicará a prática pedagógica do/da professor/a, impactando ou não na afirmativa de cultura e identidade negras e para o combate ao racismo. Dessa relação deriva a urgência de um trabalho pedagógico antirracista, visto que estudos (Valente \& Dantas, 2021) apontam que a maioria dos/das professores/as não coloca o exercício da docência a favor do trabalho com as relações étnico-raciais e que muitos não se sentem preparados para tratar de tal assunto.

Assim, os sujeitos do nosso estudo estão distribuídos, por área de ensino, como demonstra a Figura 3:

Figura 3. Área de atuação dos respondentes.

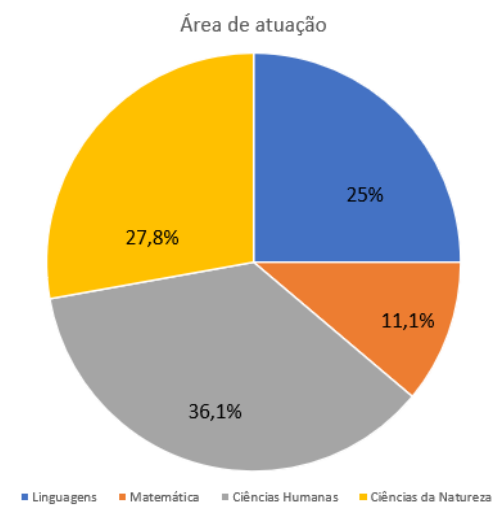

Fonte: Da pesquisa (2021).

Nota-se que a participação dos/das professores/as da área de Ciências Humanas, muito comumente evocada como principal responsável pelo trabalho com história e cultura africana e afro-brasileira, é bem superior em relação às outras. 
Ademais, somados os percentuais das áreas de Linguagens e Ciências Humanas percebe-se que o resultado encontrado é $22 \%$ maior que a soma dos percentuais das áreas de Matemática e Ciências da Natureza, áreas de conhecimento, tipicamente, consideradas menos envolvidas com práticas antirracistas.

Fez-se um recorte dos sujeitos de acordo com o sexo, que se observa na Figura 4:

Figura 4. Sexo dos respondentes.

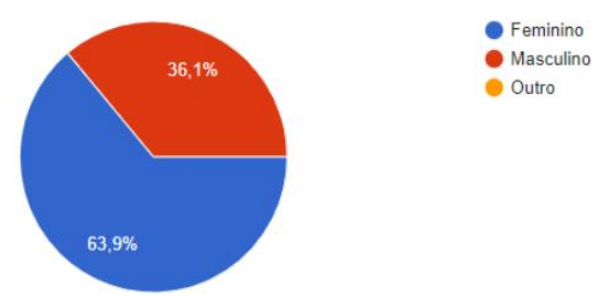

Fonte: Da pesquisa (2021).

Para a pergunta sobre a presença ou ausência de personagens negros/as nas obras por eles/as lidas não houve diferença expressiva em relação ao que foi respondido, levando em consideração o sexo dos participantes, visto que dos 36 partícipes, 23 responderam afirmativamente para a presença de personagens negros e 13 responderam que não lembravam desses personagens, do último grupo 06 eram do sexo masculino e 07 do sexo feminino. Nesse prisma, averígua-se que 36,1\% dos/as participantes revelaram não lembrarem de terem, em suas leituras literárias, a retratação de personagens negros/as.

Essa ausência pode ser compreendida a partir da contextualização historiográfica realizada por Gouvêa (2005, p. 84), quando descreve as produções literárias das duas primeiras décadas do século $\mathrm{XX}$, em que se evidencia o apagamento do/a negro/a como reflexo da sua marginalização no período pós-abolição, em que este representava a marca da escravização que deveria ser esquecida, substituída pela nova ordem social fundamentada nos ideais de progresso e civilização. Assim, o/a negro/a era "um personagem quase ausente [...] mudo, desprovido de uma caracterização que fosse além da referência racial" (Gouvêa, 2005, p. 83). Sob essa ótica, podemos refletir sobre os propósitos aos quais serviu essa forma de construir a narrativa em torno do/a personagem negro/a, e como repercutiu nas produções posteriores, ao se demonstrar nas respostas dadas à questão 2 do questionário realizado, uma parcela de participantes que não recordam de personagens negros/as em suas leituras literárias ou não são capazes de caracterizá-los, perceptível nas seguintes afirmativas presentes no Quadro 1:

Quadro 1. Respostas evasivas.

\begin{tabular}{|c|l|}
\hline Respondente & Resposta dada à questão 2 - Caracterização dos personagens negros/as em obras literárias. \\
\hline E1 & Não lembro bem. \\
\hline E5 & Todos são marcantes. \\
\hline
\end{tabular}

Fonte: Da pesquisa (2021).

Por outro lado, 63,9\% dos/as participantes afirmaram haver a presença de personagens negros/as nos textos literários lidos. Partindo desse dado, é que nos direcionamos para as respostas dadas à última pergunta (questão 2) do questionário, que solicitava que o professor descrevesse os personagens nas obras literárias, em continuidade quando a resposta afirmativa da questão 1. Os relatos obtidos são reveladores da representação destes personagens, nos auxiliam a delinear o perfil de suas características e a pensar como a construção narrativa e estética dos personagens contribuem para a reprodução e manutenção de estereótipos em torno do ser negro/a, como é possível comprovar com as informações do Quadro 2, reproduzido a seguir: 
Quadro 2. Respostas que vão ao encontro da estereotipação negativa do/a personagem negro/a.

\begin{tabular}{|c|c|}
\hline Respondente & Resposta dada à questão 2 - Caracterização dos personagens negros/as em obras literárias. \\
\hline E3 & Sempre de baixa renda e submisso aos brancos. \\
\hline E7 & Lembrança de infância: o Saci Pererê e Dona Anastácia da Obra de Monteiro Lobato. \\
\hline E8 & Ela era uma escrava que era explorada de todas as formas por seus senhores. \\
\hline E9 & $\begin{array}{l}\text { Normalmente, eram personagens excluídos da sociedade. Tinham vida muito difícil, com quase } \\
\text { nenhuma oportunidade. }\end{array}$ \\
\hline E10 & O personagem que vivia em um cortiço. Sofria muito por ser pobre e negro. \\
\hline E11 & $\begin{array}{l}\text { Raimundo, personagem de "O mulato" mesmo sendo rico e formado em Direito, foi vítima do } \\
\text { preconceito racial, na cidade de São Luís do Maranhão. }\end{array}$ \\
\hline E12 & $\begin{array}{l}\text { A discriminação é evidente na dificuldade,(comum a todos os personagens), que surge em conquistar } \\
\text { espaço na sociedade. }\end{array}$ \\
\hline E14 & $\begin{array}{l}\text { Em alguns dos livros que li, sempre foram personagens sem tanta importância na trama, pois ou eram } \\
\text { escravos ou trabalhadores braçais em engenhos, fazendas. Nunca estavam em evidência por sempre } \\
\text { estarem em uma posição social inferior. }\end{array}$ \\
\hline E15 & Geralmente esses personagens era secundários, ou estavam na cozinha ou na lavoura. \\
\hline E19 & 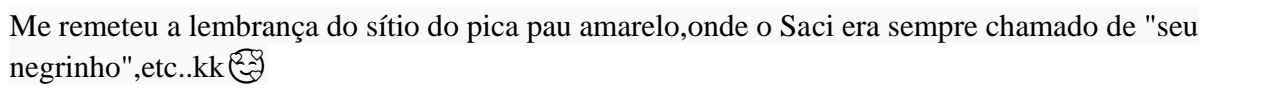 \\
\hline E22 & $\begin{array}{l}\text { Tia Nastácia do sítio do Pica-Pau amarelo, personagem de Monteiro Lobato. Ela é negra, analfabeta, } \\
\text { está sempre, eu disse, sempre na cozinha mesmo fazendo parte da família. }\end{array}$ \\
\hline E23 & Geralmente as personagens negras são marginalizadas nas narrativas ficcionais. \\
\hline
\end{tabular}

Fonte: Da pesquisa (2021).

Oliveira (2017) ao propor em seu trabalho a análise de produções literárias em determinado período histórico, buscando traçar a aparição de personagens negros/as nos enredos, consegue estabelecer categorias que sintetizam as características predominantemente atribuídas a estes personagens, como: aparência, atividade profissional, espaço social onde está inserido, origem familiar e identificação. Embora sua pesquisa seja direcionada à literatura infantojuvenil, o que a autora consegue inferir acerca da personalização dos personagens, igualmente se reflete nas afirmativas de nossos/as interlocutores/as: “são, sim, várias estórias, mas entrelaçadas pelos mesmos fios que tecem os personagens negros” (Oliveira, 2017, p. 9).

No que tange a atividade profissional, verifica-se nas assertivas dos respondentes E8, E14 e E15, presentes no Quadro 2, que os/as personagens são associados a trabalhos considerados socialmente desprestigiados, ou ainda relacionados a escravização, como o exercício braçal na lavoura, nos engenhos, nas fazendas, mulheres no papel de domésticas, restritas ao espaço da cozinha ou tendo seus corpos explorados e hipersexualizados. Em relação ao espaço e condição social, ainda no Quadro 2, nas respostas E3, E9, E10, E12, E23, nas narrativas se repetem o vínculo com a pobreza, marginalização, imersão em um contexto de submissão, fome, miséria, exclusão, sofrimento, habitação em favelas, morros, cortiços, destituição até de sua humanidade. Por um prisma diferente, Evaristo (2007, p. 21) propõe que a produção literária seja utilizada para romper esse ciclo quando afirma que "nossa Escrevivência ${ }^{6}$ não pode ser lida como histórias para 'ninar os da casa grande' e sim para incomodá-los em seus sonos injustos”.

\footnotetext{
${ }^{6}$ Conceito, criado pela escritora Conceição Evaristo, que significa "a escrita que nasce da vivência de quem escreve".
} 
Em contrapartida, mesmo quando o enredo em torno do/a personagem envereda para uma certa ascensão, este ainda é marcado pelas mazelas do racismo estruturante, visível na fala do respondente E11 (Quadro 2), quando destaca o personagem Raimundo da obra "O mulato" de Aluísio de Azevedo, em que mesmo conseguindo ascender e ocupar uma posição socialmente estimada, não está isento de passar por situações de discriminação, preconceitos velado ou escancarado, motivadas por sua origem familiar, já que Raimundo é filho de uma escravizada, como também pela cor de sua pele.

Também é significativo abordar as diversas menções aos personagens de Monteiro Lobato pelos respondentes, sobretudo de $O$ Sítio do Pica-Pau Amarelo, obra amplamente conhecida, em que adentramos a memória do acesso às produções literárias infantis. Conforme elucida Gouvêa (2005, p. 83) a imagem do/a negro/a foi da ausência à mitificação, a partir das transformações no campo cultural, em que se buscou reforçar através das produções a ideia de identidade nacional. Assim, "o negro emergia nas narrativas, de maneira mitificada, identificado com as raízes do país" (Gouvêa, 2005, p. 84).

No movimento de realizar um breve histórico sobre o protagonismo de personagens negras/os na literatura infantil, Silva et al. (2020, p. 179) ressaltam o importante lugar que a escrita literária de Monteiro Lobato passou a exercer ao se tornar um marco para a emergência da literatura infantil brasileira, com a criação de um universo mágico, fantasioso, caracterizado com elementos folclóricos da nacionalidade brasileira. Entretanto, as autoras nos chamam atenção para a ambiguidade presente nas obras produzidas por Lobato, especialmente na construção dos discursos e representação das personagens negras:

A literatura, assim como outras produções artísticas, tende a refletir os valores e ideologias presentes na sociedade. Atreladas à mentalidade eugenista, as obras lobatianas tendem a refletir posturas de inferiorização dos seus personagens negros (tia Nastácia, Barnabé, Saci Pererê), endossando estereótipos comumente atribuídos a esta população em posições de servilismo e subalternização. (Silva et al., 2020, p. 179)

Podemos inferir o que as autoras abordam, quando a respondente E19 (Quadro 2) cita: "me remeteu a lembrança do sítio do pica-pau amarelo, onde o Saci era sempre chamado de 'seu negrinho'(...)”. Como ressalta Gouvêa (2005, p. 88), a referência negra era que posicionava os/as personagens na narrativa, confirmava sua identidade, distinguindo-o dos demais, diferente do que ocorria com personagens brancos, cujas marcas raciais não eram denominadas. É possível perceber a conotação negativa que carrega o termo "seu negrinho" atribuído à figura do Saci de maneira depreciativa, com o intuito de demarcar sua alteridade.

Gomes (2005, p. 43) ao tratar sobre o conceito de identidade negra, argumenta que esta pode ser compreendida enquanto "construção social, histórica e plural", e que se faz necessário "considerá-la não somente na sua dimensão subjetiva e simbólica, mas sobretudo no seu sentido político". Concordando com o que afirma a autora, é um desafio imposto à população negra brasileira construir uma identidade positiva, no contexto de uma sociedade marcada pelo racismo estrutural e pela falácia da democracia racial, que historicamente ensina que para ser aceito é necessário negar a si mesmo, seus traços, sua cultura, sua identidade (Gomes, 2005, p. 43). Nesse sentido, Oliveira (2017, p. 4) incisivamente nos ensina sobre a necessária ressignificação do termo "negro", como proposto pelos Movimentos Negros, a fim de desconstruir o sentido diminutivo a ele colocado ao longo dos anos, reivindicando toda a luta, a memória, a história, os sujeitos sociais a quem representa.

Ainda se tratando da obra lobatiana, temos também a figura de Tia Nastácia, rememorada na resposta E22 (Quadro 2) que descreve a personagem como negra, analfabeta e de maneira contundente reitera o fato de ela estar sempre na cozinha. Assim, como explicita Gouvêa (2005, p. 84) a negra e o negro velho passaram a ser personagens constantes, agentes socializadores das crianças brancas, como a Tia Nastácia, que em um breve momento da obra de Monteiro Lobato foi convidada a ser contadora de histórias, mas logo constatou-se que não servia para tal ocupação, e reassumiu seu lugar na cozinha, "numa posição de servidão que revela a continuidade com o modelo escravocrata" (Gouvêa, 2005, p. 84). 
Além disso, a resposta do participante E20, presente no Quadro 3, reproduzido a seguir, apresenta indícios que podem ser reveladores do ideal de branqueamento da sociedade brasileira. De acordo com Bernardino (2002) "o ideal de embranquecimento pressupunha uma solução para o problema racial brasileiro através da gradual eliminação do negro, que seria assimilado pela população branca". Dessa forma, a ideia de que, devido à miscigenação, a população brasileira estaria a caminho do embranquecimento e de que essa condição seria necessária para apresentar caráter positivo e ser capaz de bons feitos é reforçada em obras, em alguns momentos, tomadas como romances abolicionistas, como é o caso de "A escrava Isaura", de Bernardo Guimarães.

Quadro 3. Resposta que condiz com a ideia de embranquecimento do/a negro/a.

\begin{tabular}{|l|l|}
\hline E20 & $\begin{array}{l}\text { A escrava Isaura, de Bernardo Guimarães. Existiam personagens negros, mesmo Isaura não sendo } \\
\text { preta, ela contribuiu para impactar a sociedade na época, em relação à abolição da escravidão. }\end{array}$ \\
\hline
\end{tabular}

Fonte: Da pesquisa (2021).

Por outro lado, é possível perceber, em alguns relatos, a presença de personagens e autores/as que apontam para o rompimento da ideia pré-estabelecida sobre o "ser negro", segundo afirma Cuti $(2010$, p. 25) “[...] as rupturas desse círculo têm sido realizadas principalmente pelas suas próprias vítimas e por aqueles que não se negam a refletir profundamente acerca das relações raciais no Brasil”. Como é possível verificar no Quadro 4:

Quadro 4. Respostas que vão de encontro à estereotipação negativa do negro/a.

\begin{tabular}{|c|c|}
\hline $\mathrm{E} 2$ & $\begin{array}{l}\text { Foram tantos: em Becos da Memória de Conceição Evaristo destaco - Negro Alírio, Maria Nova, Tio } \\
\text { Totó todos moradores da favela que estava no precessão de urbanização vivendo as dores de não } \\
\text { aceitar perder seu lugar, sua identidade, seu espaço. } \\
\text { Um Defeito de Cor - Kehind, a menina que foi capturada em África junto com sua avó e irmã, foi } \\
\text { feita escrava no Brasil, se envolveu na revolta dos males e viveu a dor de ter o filho que nasceu livre } \\
\text { ter sido vendido como escravo pelo pai. } \\
\text { Torto Arado - relata a saga das irmãs Bibiana e Belonisa que lutam pelo direito de viver com } \\
\text { dignidade no campo tirando da terra o sustento para suas famílias, lutam também pelo direito de suas } \\
\text { tradições religiosas. } \\
\text { A Gloriosa Família - O escrevo sem nome, identificado nas palavras dele " meu dono Baltazar Van } \\
\text { Dun que conseguiu se fazer de tolo, idiota e o dono dizia que ele não sabia de nada, ledo engano, o } \\
\text { escravo sabia tudo, tudo mesmo, inclusive sabia falar francês. }\end{array}$ \\
\hline $\mathrm{E} 4$ & $\begin{array}{l}\text { Muitas história, principalmente da formação do nosso país. São tristes e vivenciamos até hoje essa } \\
\text { negação de direitos e preconceitos. }\end{array}$ \\
\hline E6 & $\begin{array}{l}\text { Carolina Maria de Jesus escreveu "Quarto de despejo: diário de uma favelada". Trata da historia de } \\
\text { uma mulher negra, moradora de uma favela que ganhava a vida com reciclagem que enfrenta muitas } \\
\text { dificuldade na vida mas consegue vencer. }\end{array}$ \\
\hline E13 & Infelizmente, os personagens eram tratados como meros coadjuvantes. \\
\hline E16 & São personagens marcados pela resistência, pela fé, pela luta. \\
\hline E18 & Personagens de personalidade forte e destemidos. \\
\hline E21 & $\begin{array}{l}\text { Em um defeito de cor, Becos da memória, Olhos d'água, Ponciá Vicêncio, Quarto de despejo, Pai } \\
\text { contra mãe e tantos outros vejo o preconceito e discriminação que sofrem, mas também vejo e } \\
\text { aplaudo a força de resistência desse povo que tanto admiro. }\end{array}$ \\
\hline
\end{tabular}

Fonte: Da pesquisa (2021).

É possível perceber que, na fala do/da respondente E4, há uma consciência de persistência da desigualdade de condições pela cor/raça dos sujeitos, quando afirma que “...vivenciamos até hoje essa negação de direitos e preconceito”. Isso 
é revelador do rompimento com o mito da democracia racial, amplamente divulgado depois da publicação da obra CasaGrande e Senzala, do sociólogo Gilberto Freyre, que traz uma ideia estruturante de nacionalismo brasileiro, a ponto de desconsiderar as diferentes camadas sociais da sociedade e apregoar a noção de que o desempenho profissional, pessoal, social do sujeito está ligado apenas a esforço pessoal, o que não condiz com a realidade (Bernardino, 2002, p. 250).

Constata-se também a recorrência de vocábulos de cunho positivo para caracterizar os/as personagens negros/as, nas palavras dos respondentes E16 e E18, ratificando o que aponta Santos (2018) quando afirma que "torna-se importante para que o público leitor tenha contato com ideias positivas (tão raras) de negros brasileiros". Infere-se ainda que falas como essas são também possibilitadas pelo irreversível e potente movimento literário vivenciado no Brasil, especialmente pela produção de mulheres negras, como é possível perceber nas falas dos/as respondentes E2, E6 e E21. De tal maneira, essas obras contribuem para descortinar a história, construir novas narrativas, decolonizar o conhecimento, corroborando o pensamento de Adichie (2019, p. 33) quando afirma que “...quando rejeitamos a história única, quando percebemos que nunca existe uma história única sobre lugar nenhum, reavemos uma espécie de paraíso".

\section{Conclusão}

No contexto brasileiro, há uma clara identificação negativa sobre a ideia do "ser negro" e isso está relacionado às memórias que foram construídas ao longo da história e ao fato de que elas foram elaboradas tendo por base o pensamento eurocentrado e discriminatório em relação aos povos negros. Fala-se nos contributos da cultura africana ao povo brasileiro, porém reflexões críticas a respeito de como nossa história foi contada e até sobre a realidade desigual em que vive a população negra brasileira ainda são pouco possibilitadas, além de ainda haver ampla defesa de concepções que afirmam que desfrutamos de uma democracia racial.

O presente trabalho apresenta dados que nos possibilitam refletir sobre a figura do negro na trajetória de leituras literárias feitas por professores de Ensino Médio de uma instituição escolar na região do Cariri, oportunizando a revelação de que o percurso de elaboração do que é "ser negro" é atravessado pela literatura e que para ações interventivas para a problemática discutida neste artigo, essa área do conhecimento torna-se um potente instrumento.

Verificou-se, pelas falas dos/das educadores/as que o passado escravocrata e desigual ainda persiste na nossa sociedade, não só por meio de dados alarmantes, mas também no nosso imaginário que é refletido nos nossos discursos, posicionamentos, práticas, atitudes. De tal maneira, para que haja a correção do reconhecimento distorcido e da estigmatização, os/as professores/as apresentam-se como agentes fundamentais nesse processo, pois são aqueles que por meio de suas práticas proporcionarão um caminho diferente daquele ditado pela "história única". O não silenciamento perante os conflitos de discriminação será um fator indispensável para sua eliminação e para a construção de uma educação emancipatória, que promova o respeito e a cidadania de todos/as, nesse sentido, o/a educador/a deve estar aberto a refletir criticamente sobre sua prática e à possibilidade de modificá-la, reconstruí-la em dimensões antirracistas.

De tal modo, torna-se de fundamental importância que novos estudos acerca dessa temática sejam desenvolvidos, principalmente no tocante à relação entre a visão do professor/a sobre o "ser negro" e sua prática pedagógica e desta com as relações étnico-raciais. Para artigos e trabalhos futuros, indicamos que a investigação seja feita com educadores/as de diferentes níveis de ensino, considerando o tempo de formação inicial e a possibilidade de formação continuada no tocante ao ensino por práticas antirracista e, para averiguação de resultados, o estudo pode ser realizado em outro município e/ou região.

\section{Agradecimentos}

Aos sujeitos participantes da pesquisa que aceitaram compartilhar suas memórias e assim permitir a construção de nosso trabalho. Ao Instituto Federal do Ceará e à Universidade da Integração Internacional da Lusofonia Afro-Brasileira. 


\section{Referências}

Adichie, C. N. (2019). O perigo de uma história única. Companhia das Letras.

Bernardino, J. (2002). Ação afirmativa e a rediscussão do mito da democracia racial no Brasil. Estudos Afro-Asiáticos, 24(2) , 247-273. https://doi.org/10.1590/S0101-546X2002000200002.

Brasil. (2003). Lei 10.639 de 9 de janeiro de 2003. Altera a Lei de diretrizes e bases da educação Nacional $9394 / 1996$ e inclui Ensino da História e cultura Afro-brasileira e Africana no Currículo Oficial e outras Providências. Brasília: Diário Oficial da União, 10(01).

Brasil. (2006). Orientações Curriculares Nacionais de Língua Portuguesa Ensino Médio - OCNEM. Ministério da Educação.

Cuti, L. S. (2010). Literatura negro-brasileira. Selo Negro.

Evaristo, Conceição (2007). Da grafia-desenho de minha mãe, um dos lugares de nascimento de minha escrita. In: Alexandre, M. A. (Org..) Representações performáticas brasileiras: teorias, práticas e suas interfaces. Mazza Edições, p. 16-21.

Freire, P. (1996). Pedagogia da autonomia. Paz e Terra.

Gomes, N. L. (2005). Alguns termos e conceitos presentes no debate sobre relações raciais no Brasil: uma breve discussão. Educação antirracista: caminhos abertos pela Lei Federal n 10.639/03. Brasília: MEC/SECAD, 39-62.

Gonsalves, E. P. (2007). Conversas sobre iniciação à pesquisa científica. Editora Alínea.

Gouvêa, M. C. S. (2005). Imagens do negro na literatura infantil brasileira: análise historiográfica. Educação e Pesquisa, São Paulo, 31 (1), 79-91.

IBGE - Instituto Brasileiro de Geografia e Estatística. (2020). Pesquisa Nacional por Amostra de Domicílios PNAD Covid-19 - microdados.

Lopes, B. A. de L., \& Silva, G. C. (2021). Questionário para pesquisa Literatura negro-brasileira e relações étnico-raciais: possibilidades em “Olhos d'água", de Conceição Evaristo. Respondido por vários professores/as. Juazeiro do Norte.

Oliveira, M. A. J. (2017). A tessitura dos personagens negros na Literatura Infantojuvenil Brasileira. Literafro. http://www.letras.ufmg.br/literafro/artigos/artigos-teorico-criticos/120-maria-anoria-de-jesus-oliveira-a-tessitura-dos-personagens-negros-na-literaturainfantojuvenil-brasileira.

Santos, M. C. (2018). Intelectuais negras: prosa negro-brasileira contemporânea. Malê.

Silva, E. B. S. et al. (2020) Protagonistas negros na literatura infantil brasileira: breve histórico e perspectivas contemporâneas. Humanidades \& Inovação, $7(22), 177-187$.

Silva, G. C. (2009) O uso de literatura africana e afrodescendente junto a crianças de escolas públicas de Fortaleza: construindo caminhos para repensar o negro. [Dissertação de mestrado, Faculdade de Educação da Universidade Federal do Ceará]. Repositório Institucional da Universidade Federal do Ceará. http://www.repositorio.ufc.br/handle/riufc/3414.

Silva, K. dos S. \& Boakari, F. M. (2021). O corpo afrodescendente e a escola: narrativas pessoais como possibilidades de superação do racismo. Research, Society and Development, 10(12). http://dx.doi.org/10.33448/rsd-v10i12-19998.

Sousa, A. L. de. (2005). Personagens negros na literatura infanto-juvenil: rompendo esteriótipos. In: Cavalleiro, E. Racismo e anti-racismo na educação: repensando nossa escola. Summus.

Valente, G., \& Dantas, A. S. R. (2021). Práticas docentes e relações étnico-raciais: Reflexos da sociedade brasileira. Cadernos de Pesquisa, 51 , Artigo e07327. https://doi.org/10.1590/198053147327.

Xavier, A. R., Fialho, L. M. F., \& Vasconcelos, J. G. (2018). História, Memória e Educação: aspectos conceituais e teórico-epistemológicos. EdUECE. 